\title{
Overview: Canada's Generation IV International Forum (GIF) Participation and National Program
}

\author{
DANIEL BRADY ${ }^{1,2}$ and CHERI-ANN MACKINLAY ${ }^{1}$ \\ 1.--Natural Resources Canada, 580 Booth Street, Ottawa, ON K1A 0E4, Canada. \\ 2.—e-mail: daniel.brady@canada.ca
}

Canada is one of a few nations having its own nuclear reactor technologies, fuel fabrication capabilities and a wealth of uranium resources. Canada has developed and safely operated a fleet of Canada Deuterium Uranium (CANDU) nuclear power reactors for over 50 years. There are 19 operational CANDU reactors in Canada, plus 12 outside Canada. ${ }^{1}$ In 2014, nuclear power accounted for about $16 \%$ of Canada's total electricity production, and is an industry that is valued at more than Can $\$ 5$ billion which directly employs approximately 30,000 Canadians. ${ }^{2}$

Canada along with other countries has recognized the importance that nuclear energy can play in a carbon-constrained environment. In this way, nuclear energy is a non-greenhouse gas-emitting base-load energy source that can able to help achieve the dual goals of energy security and environmental sustainability. In 2000, in order to foster the development of the next generation of nuclear reactors, the international nuclear community came together with the understanding that no single nation could overcome the technological and engineering challenges in a timely manner, commit the long-term resources required, and afford the costs and risks associated with building the next generation of nuclear energy systems. In 2001, Argentina, Brazil, Canada, France, Japan, Republic of Korea, South Africa, the United Kingdom and the United States initiated the Generation IV International Forum (GIF) by signing the GIF Charter to collaboratively undertake research and development (R\&D) on the next generation of nuclear energy systems. In 2011, the Charter was renewed by the original nine members plus Switzerland, European Atomic Energy Community (EURATOM), the People's Republic of China and the Russian Federation.

In support of the GIF Charter, an international panel consisting of about 100 nuclear experts from members of the GIF reviewed nearly 100 reactor concepts and identified the six most promising nuclear reactor systems that could best meet the
GIF goals. The systems were evaluated against four broad goals of sustainability, economics, safety and reliability, together with proliferation resistance and physical protection. These systems were to be licenced, constructed and operated in such a manner that they would provide a competitively priced and reliable supply of energy in a safe and sustainable way. The result was the GIF Roadmap initially published in 2002 and updated in January 2014.

On February 28, 2005, Canada, France, Japan, and the United States signed the Framework Agreement for International Collaboration on R\&D of Generation IV Nuclear Energy Systems. This treaty set the stage for the first ever multilateral collaboration endeavour in nuclear energy R\&D. Since then, the People's Republic of China, the Republic of Korea, South Africa, the Russian Federation, Switzerland and EURATOM have signed the Framework Agreement.

As a result of signing the Framework Agreement, in 2006, the Department of Natural Resources Canada (NRCan) established Canada's Generation IV National Program (Gen-IV National Program) to support Generation IV R\&D specifically relevant to Canada and to meet Canada's commitment to GIF.

The Gen-IV National Program was designed to foster R\&D collaboration among federal laboratories, universities and industry by prioritizing projects that bring together multiple participants. In terms of international linkages, the Gen-IV National Program is the vehicle through which Canadian nuclear researchers have the means to make commitments to support international nuclear developments in collaboration with researchers from around the world. Canada's GenIV National Program is delivered through two main mechanisms. The first is through a university-based research program called the NSERC/NRCan/AECL Generation IV Energy Technologies Program. GenIV projects are funded in partnership with the Natural Sciences and Engineering Research Council of Canada (NSERC) and NRCan's Office of 
Energy Research and Development (OERD), with Atomic Energy of Canada Limited's (AECL, now called the Canadian Nuclear Laboratories, CNL) experts collaborating with university researchers and providing in-kind support in the form of expertise, materials and equipment. ${ }^{3}$ An ad hoc facilityaccess program between NSERC and NRCan's CanmetMATERIALS has enabled the universities under NSERC-funded projects to use the unique equipment for materials-related research. The second is with the national energy science and technology community, which includes federal laboratories, agencies, and crown corporations. At all times, the program encourages collaboration among the proponents, federal laboratories, industry, and universities working together on a projectby-project basis in areas of common interest.

Of the six nuclear systems endorsed by the GIF, Canada's Gen-IV National Program focused on supporting the development of a Supercritical Water-cooled Reactor (SCWR) technology. The decision to participate in the SCWR was driven primarily by a desire to leverage Canada's existing nuclear expertise and current infrastructure, and to undertake research that will most strongly contribute to technology transfer and Canadian nuclear industry growth in the short, medium and long term. The SCWR is viewed by Canadian experts as the most natural evolution of Canada's CANDU technology. Moreover, it is believed that water-cooled reactors will continue to be a mainstay of nuclear electricity production over the next 50 years.

The GIF has established System Steering Committees to implement the R\&D for each GIF System with participation from GIF Members interested in contributing to collaborative R\&D. ${ }^{4}$ Each System Steering Committee plans and integrates collaborative R\&D projects focused on areas of common interest that contribute to the development of a system. As part of the role of the System Steering Committees, System Research Plans have been developed to provide direction and to support the establishment of collaborative $R \& D$ projects. Canada, Japan, EURATOM, China, and Russia are currently signatories to the GIF SCWR System Arrangement. Within the SCWR system arrangement, two collaborative research projects have been established: materials and chemistry, and thermalhydraulics and safety. Two provisional SCWR R\&D projects are under development: fuel qualification, and system integration and assessment.

The materials and chemistry project involves the selection and testing of key materials for use both in-core and out-of-core, for both pressure tube and pressure vessel designs. Reference water chemistry has been part of the investigation, based in large part on materials compatibility and the radiolysis behaviour. $^{5}$
The Canadian Gen-IV National Program has resulted in a Canadian SCWR concept that would see an outlet temperature of $625^{\circ} \mathrm{C}$ and a system outlet pressure of $25 \mathrm{MPa}$ with peak fuel cladding temperature at about $800^{\circ} \mathrm{C}$. In order to meet the challenging design parameters, materials selection for the high-temperature components had to consider many factors including operating conditions, mechanical strength, corrosion resistance, stress corrosion cracking resistance, irradiation damage resistance, weldability and the feasibility to manufacture the relevant components. In order to better understand these conditions and obtain data to support the selection of the materials, the NSERC/NRCan/AECL University Program funded 13 projects at various universities to support materials research. As a result of Canada's Gen-IV National program, some existing facilities were upgraded and new state-of-the-art experimental facilities in Canada were established, at CanmetMaterials, CNL, and various universities, allowing for the generation of a significant amount of data required to support the development of the Canadian SCWR concept.

As a result of knowledge gained over the last 8 years, the Canadian SCWR concept has gone through various changes in order to address the demanding operating and (unlikely) accidental conditions expected. The original Canadian concept had horizontal configuration with on-line refuelling. The most recent concept has moved to a batch refuelling, vertical pressure-tube configuration with a re-entrant fuel channel design. In February 2015, the Canadian SCWR Conceptual design passed the Canadian Expert Review, and a successful international review process was held in October, 2015.

Though the program had components of research in the areas of balance of plant, physics, design and integration thermal-hydraulics and safety, the largest component (in terms of funding support) was focused on materials and chemistry. While other areas of research have been published elsewhere, relevant materials-related highlights from this Canadian program are reported in this issue of JOM.

\section{REFERENCES}

1. Canadian Nuclear Association, https://cna.ca/technology/en ergy/candu-technology/. Accessed 28 Nov 2015.

2. The Canadian Nuclear Fact Book, Canadian Nuclear Association, Ottawa, ON, Canada (2015), https://cna.ca/wp-con tent/uploads/2015/03/CNA-Factbook-2015-English1.pdf. Accessed 28 Nov 2015

3. T. Anderson, L.K.H. Leung, D. Guzonas, D. Brady, J. Poupore, and W. Zheng, Proceedings of the 19th Pacific Basin Nuclear Conference (PBNC 2014) (Toronto, ON, Canada: Canadian Nuclear Society, 2014), pp. 3022-3033.

4. Generation IV International Forum, https://www.gen-4.org/ gif/jcms/c_9343/system-arrangements-mou. Accessed 28 Nov 2015 .

5. H. Kartabil, Proceedings GIF Symposium, pp. 143-148. 